\title{
GCU
}

Glasgow Caledonian

University

University for the Common Good

\section{Predictive voltage control of phase-controlled series-parallel resonant converter}

Aboushady, A.A.; Ahmed, K.H.; Adam, G.P.; Williams, B.W.

Published in:

4th International Conference on Power Engineering, Energy and Electrical Drives

DOI:

10.1109/PowerEng.2013.6635752

Publication date:

2013

Document Version

Author accepted manuscript

Link to publication in ResearchOnline

Citation for published version (Harvard):

Aboushady, AA, Ahmed, KH, Adam, GP \& Williams, BW 2013, Predictive voltage control of phase-controlled series-parallel resonant converter. in 4th International Conference on Power Engineering, Energy and Electrical Drives. IEEE, 2013 Fourth International Conference on Power Engineering, Energy and Electrical Drives (POWERENG), Istanbul, Turkey, 13/05/13. https://doi.org/10.1109/PowerEng.2013.6635752

\section{General rights}

Copyright and moral rights for the publications made accessible in the public portal are retained by the authors and/or other copyright owners and it is a condition of accessing publications that users recognise and abide by the legal requirements associated with these rights.

Take down policy

If you believe that this document breaches copyright please view our takedown policy at https://edshare.gcu.ac.uk/id/eprint/5179 for details of how to contact us. 


\title{
Predictive Voltage Control of Phase-Controlled Series-Parallel Resonant Converter
}

\author{
A.A.Aboushady+, K.H.Ahmed*, G.P.Adam+, and B.W.Williams + \\ +Department of Electrical and Electronics Engineering, University of Strathclyde, Glasgow, United Kingdom \\ *Electrical Engineering Department, Faculty of Engineering, Alexandria University, Alexandria, Egypt \\ ahmed.aboushady@strath.ac.uk,khaled.ahmed@ieee.org
}

\begin{abstract}
This paper proposes a predictive output voltage controller for the phase-controlled series-parallel resonant converter. The objective of this controller is to enhance closed loop system robustness and dynamic performance compared to conventional PI control. First, the converter non-linear large signal behavior is linearized using a state feedback based scheme. Consequently, the converter preserves its large signal characteristics while modeled as a linear system. A reduced order model is then used for the detailed design of the proposed predictive controller. Stability analysis and controller gains selection are addressed. Finally, simulation and experimental results are demonstrated to validate the improved system performance in contrast with PI control.
\end{abstract}

Keywords-Phase control, predictive control, robustness, seriesparallel resonant converter (SPRC).

\section{INTRODUCTION}

Resonant converters are an alternative to hard-switched PWM converters in dc power supply applications. This is due to their soft switching characteristics; hereby boosting switching frequency and reducing converter footprint. This feature has been very attractive in modular multi-cell $\mathrm{dc} / \mathrm{dc}$ converters catering for fault tolerant high power dc supplies.

The series-parallel resonant converter (SPRC) has been one of the main resonant converter topologies subject to rigorous research in the past [1-6]. It can operate over a large input voltage range and a large load range (no load to full load) while maintaining high efficiency. Several linear and nonlinear control techniques have been reported for SPRC [7-10]. Among them, non-linear techniques have received particular attention due to the improvement of the transient response, robustness, and stable behaviour against load and input voltage variations. However, non-linear control laws are usually complex, which makes practical control implementation difficult. Fast, simple and robust sliding-mode controllers were proposed for a zero current switching (ZCS) SPRC operating with quantum-mode control [11]. A sliding mode controller design approach was applied in [12] to a zero voltage switching (ZVS) SPRC using the self-sustained phase shift modulation technique introduced in [13]. The latter technique, although providing ZVS for the whole load range with good output voltage regulation, varies the switching frequency to obtain this goal. Practically, varying switching frequency is undesirable due to EMI problems. For this reason, this paper focuses on the fixed frequency phase control technique of SPRC [14-19].

Conventional PI control design methods based on small signal modelling of the converter depend on linearizing converter large signal model around an equilibrium point. Although eliminating error in output voltage, dynamic response is only satisfactory in a close neighbourhood to the steady state operating point selected [20]. In addition, under PI control, high proportional gain is necessary to achieve high system robustness, disturbance rejection capability and dynamic performance. This results in lower closed loop stability margins and oscillatory system behaviour. To achieve better robustness and dynamic performance with reasonable closed loop stability, this paper proposes a predictive output voltage controller for the phase-controlled SPRC based on a two-loop structure. The derivation of the controller structure is based on linearizing the converter large signal model using a state feedback scheme where output filter inductor current is sensed and used for linearization. This facilitates the controller design procedure.

The paper is organised as follows. In section two, the converter model and state feedback linearization scheme are outlined [21]. Predictive controller design is addressed in section three. Stability analysis is given in section four and accordingly controller gains are selected. Finally, simulation and experimental results are used to validate controller performance in section five.

\section{SPRC LINEARIZED LARGE SIGNAL MODEL}

Fig. 1 shows the circuit diagram for a typical SPRC. Two stages of conversion exist; dc/ac (inversion) and ac/dc (rectification). Hence, two main subsystems exist; the ac subsystem (resonant tank and transformer) and the dc sub-system (output filter), as illustrated in Fig. 2. Each sub-system has its own state variables; therefore, both ac and dc state variables exist. 


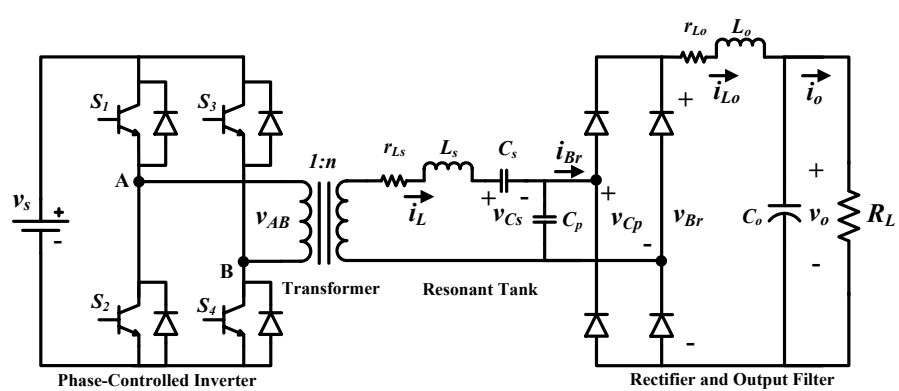

Fig. 1. Circuit diagram for the SPRC.

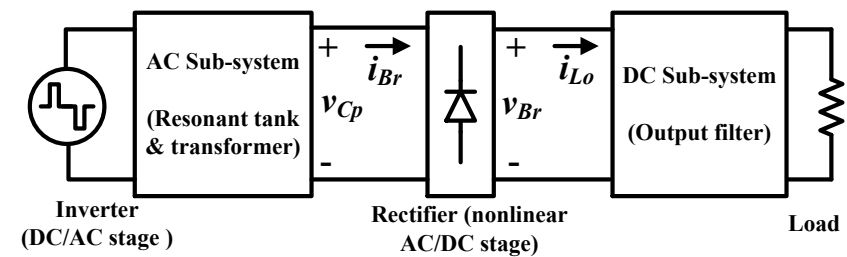

Fig. 2. SPRC conversion stages and subsystems.

In order to combine both types of signals into one model, it is essential to transform the ac state variables to equivalent dc quantities. This is achieved with the multiple frequency modeling technique which converts the ac state variables to $d$ $q$ quantities using the harmonic balance theory [22]. The resulting dc state variables from the resonant tank are combined with the natural dc state variables of the output filter side (modeled with conventional average state-space modeling) using a linearization scheme to overcome the nonlinearity imposed by the rectifier. The result is an aggregate large signal linear model for the complete converter.

\section{A. Ac sub-system modeling}

Fig. 3(a) illustrates the ac subsystem equivalent circuit, where $v_{A B}$ is the inverter output voltage referred to secondary and $r_{T}$ with $L_{T}$ represent the total equivalent series impedance taking into account transformer copper resistance and leakage inductance respectively. Applying harmonic balance theory and assuming fundamental ac components only with angular frequency $\omega_{s}$, model can be represented by

$$
\vec{x}_{1}(l)=A_{1} \vec{x}_{1}(l)+D_{1} \vec{u}(l)
$$

where

$$
\begin{aligned}
& \left.\vec{x}_{1}(\iota)=\iota_{L d} i_{L q} v_{C s d} v_{C s q} v_{C p d} v_{C p q}\right]^{T}, \vec{u}_{1}(\iota)=\left[v_{A B d} v_{A B q} i_{B r d} i_{B r q}\right]^{T} \text {, } \\
& A_{1}=\left[\begin{array}{cccccc}
-\frac{r_{T}}{L_{T}} & \omega_{s} & -\frac{1}{L_{T}} & 0 & -\frac{1}{L_{T}} & 0 \\
-\omega_{s} & -\frac{r_{T}}{L_{T}} & 0 & -\frac{1}{L_{T}} & 0 & -\frac{1}{L_{T}} \\
\frac{1}{C_{s}} & 0 & 0 & \omega_{s} & 0 & 0 \\
0 & \frac{1}{C_{s}} & -\omega_{s} & 0 & 0 & 0 \\
\frac{1}{C_{p}} & 0 & 0 & 0 & 0 & \omega_{s} \\
0 & \frac{1}{C_{p}} & 0 & 0 & -\omega_{s} & 0
\end{array}\right] B_{1}=\left[\begin{array}{cccc}
\frac{1}{L_{T}} & 0 & 0 & 0 \\
0 & \frac{1}{L_{T}} & 0 & 0 \\
0 & 0 & 0 & 0 \\
0 & 0 & 0 & 0 \\
0 & 0 & -\frac{1}{C_{p}} & 0 \\
0 & 0 & 0 & -\frac{1}{C_{p}}
\end{array}\right]
\end{aligned}
$$

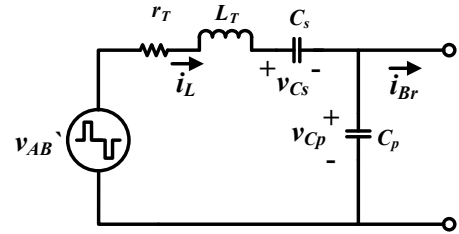

(a)

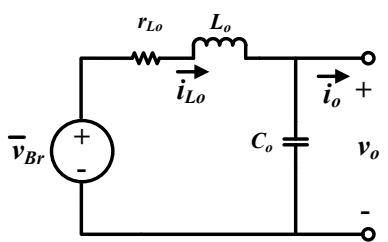

(b)
Fig.3. Equivalent circuit diagram for (a) ac sub-system, and (b) dc sub-system.

\section{B. Dc sub-system modeling}

Fig. 3(b) shows the equivalent circuit diagram for the SPRC dc sub-system. Note that $\bar{v}_{B r}$ is the average rectifier output voltage $v_{B r}$. Energy is transferred at dc frequency, so the dominant component for modeling and analysis is the $\mathrm{dc}$ (average) value. For this reason, average state-space modeling is valid for modeling the dc sub-system

$$
\vec{x}_{2}(\iota)=\mathrm{A}_{2} \vec{x}_{2}(\iota)+D_{2} \vec{u}(\iota)
$$

where

$$
\vec{x}_{2}(\iota)=\left\lfloor\iota_{L o} v_{o}\right]^{T}, \vec{u}_{2}(\iota)=\left[v_{B r} i_{o}\right]^{T}, A_{2}=\left[\begin{array}{cc}
-\frac{r_{L o}}{L_{o}} & -\frac{1}{L_{o}} \\
\frac{1}{C_{o}} & 0
\end{array}\right], B_{2}=\left[\begin{array}{cc}
\frac{1}{L_{o}} & 0 \\
0 & -\frac{1}{C_{o}}
\end{array}\right]
$$

\section{Combined system non-linear model}

Fig.4 shows the non-linear model for the SPRC combining the state-space linear models of the ac and dc sub-systems. The mathematical square-root function represents the action the rectifier in Fig.2 linking the peak parallel capacitor voltage $v_{C p}$ to rectifier output voltage $v_{B r}$. If this non-linear mathematical relation is omitted, the entire large signal converter model becomes linear.

\section{Linearization using state feedback scheme}

The objective of the linearization scheme is to force either $v_{C p d}=0$ or $v_{C p q}=0$ to eliminate the mathematical non-linearity. This is obtained by orientation of the ac sub-system dq frame such that input voltages $v_{A B d}{ }^{\prime}$ and $v_{A B q}{ }^{\prime}$ are calculated accordingly to obtain $v_{C p d}=v_{c}$ (the control variable) and $v_{C p q}=0$. To obtain this, a state feedback measurement from output filter inductor current $i_{L o}$ is necessary. Fig. 5 shows how the state feedback scheme linearizes SPRC model. Coefficients $k_{1}, k_{3}, k_{5}$ and $k_{7}$ are circuit parameter dependent. Detailed in-depth analysis and derivation is given by the authors in [21].

\section{E. Reduced order model}

After linearizing the SPRC model, the resultant aggregate model is of eighth order due to combining both ac and dc subsystems. This makes analysis and controller design a very cumbersome task. The state feedback linearization scheme ensures always that the two main conditions are satisfied

$$
v_{C p d}=v_{c} \text { and } v_{C p q}=0
$$

Therefore, the following relation is satisfied

$$
\bar{v}_{B r}=\frac{2}{\pi} \sqrt{{v_{C p d}{ }^{2}+v_{C p q}^{2}}^{2}}=\frac{2}{\pi} v_{c}
$$




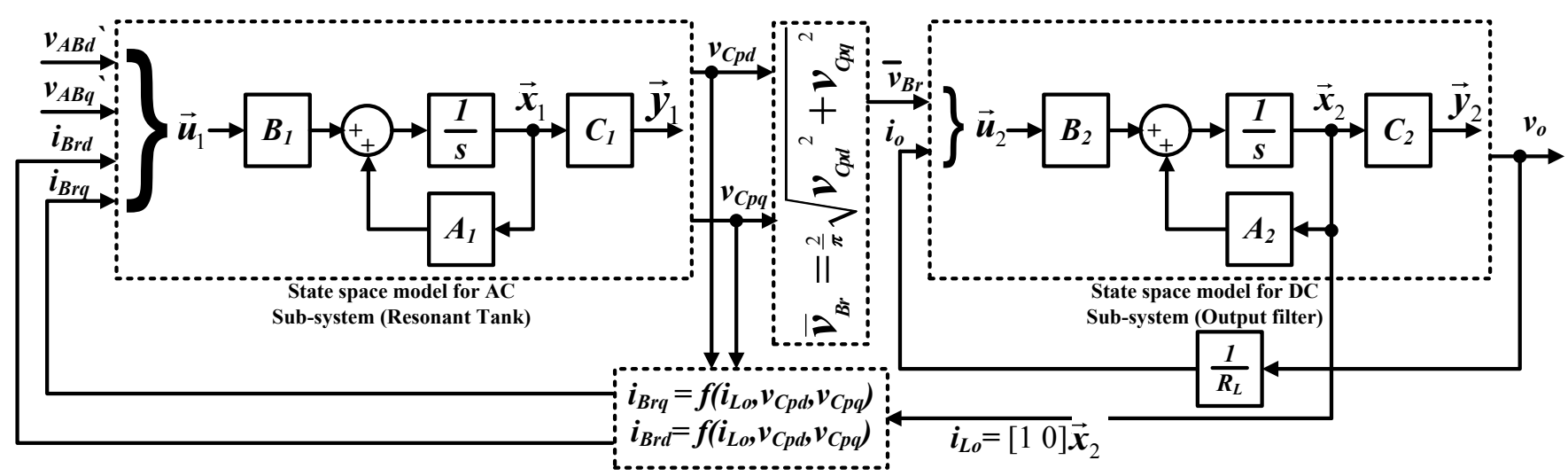

Fig. 4. Non-linear combined system model for the SPRC.

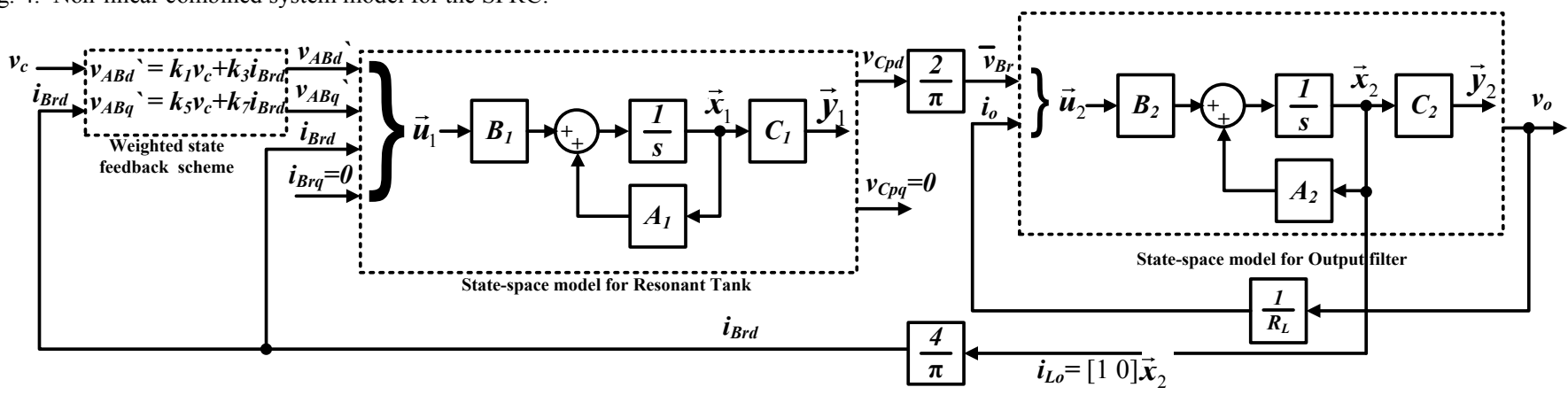

Fig. 5. Linearized model for the SPRC using weighted state feedback.

Consequently, control-to-output voltage transfer function can be approximated by the output filter circuit

$$
\frac{v_{o}(s)}{v_{c}(s)} \approx \frac{2}{\pi} \frac{v_{o}(s)}{\bar{v}_{B r}(s)} \approx \frac{2}{\pi} \frac{1}{L_{o} C_{o} s^{2}+r_{L o} C_{o} s+1}
$$

This reduces the eighth order system model to a second order model, thanks to the slow output filter dynamics which dominate converter output voltage response compared to the fast resonant tank dynamics.

\section{PREDICTIVE CONTROLLER DESIGN}

Predictive control is a common control algorithm in applications such as active power filters, PWM rectifiers, current control of PWM inverters, ac drives, and distributed generation systems. Its application in the discrete time domain makes it suitable for DSP implementation. Predictive control of the phase-controlled SPRC has not been previously investigated. A two loop controller is designed with the outer loop performing output voltage regulation.

Since the reduced order SPRC model approximates the converter large signal model by the output filter (dc subsystem) model, therefore substituting (4) into (2) yields

$$
\begin{aligned}
& \frac{d i_{L o}}{d t}=\frac{1}{L_{O}}\left(-r_{L o} i_{L o}-v_{O}+\frac{2}{\pi} v_{c}\right) \\
& \frac{d v_{O}}{d t}=\frac{1}{C_{O}}\left(i_{L o}-i_{O}\right)=\frac{1}{C_{O}}\left(i_{L o}-\frac{1}{R_{L}} v_{O}\right)
\end{aligned}
$$

Discretizing (6) yields

$$
v_{C}(k)=\frac{\pi}{2}\left(r_{L o} i_{L o}(k)+\frac{L_{O}}{T_{S}}\left(i_{L o}(k+1)-i_{L o}(k)\right)+v_{o}(k)\right)
$$

$$
{ }^{i_{C O}}(k)=i_{L O}(k)-i_{O}(k)=\frac{C_{O}}{T_{S}}\left(v_{O}(k+1)-v_{O}(k)\right)
$$

where $T_{s}$ is the sampling (switching) frequency. Considering (8) and replacing $v_{o}(k+1)$ for $v_{o}{ }^{*}(k+1)$ and $i_{C o}(k)$ for $i_{C o}{ }^{*}(k)$, the output voltage loop can be constructed as

$$
i_{C o}{ }^{*}(k)=k_{1}\left(v_{O}^{*}(k+1)-v_{O}(k)\right)
$$

where $k_{l}$ is the voltage loop predictive gain designed to obtain fast and stable response. With a high switching frequency (40 $\mathrm{kHz}$ ), change in load current $i_{o}(k)$ can be neglected compared to change in $i_{L o}(k)$ and $i_{C o}(k)$, hence it is an acceptable approximation to state that

$$
\begin{aligned}
& i_{O}(k)=i_{O}(k+1) \\
& i_{L o}(k+1)-i_{L o}(k)=i_{C o}(k+1)-i_{C o}(k)
\end{aligned}
$$

Substituting for instant $(k+1)$ by $k$ in (9) yields the modified outer voltage loop structure

$$
i_{C o}{ }^{*}(k+1)=k_{1}\left(v_{o}{ }^{*}(k+2)-v_{o}(k+1)\right)
$$

Equating $i_{C o}(k+1)$ to $i_{C o}{ }^{*}(k+1)$ in equation (10) yields

$$
i_{C o}{ }^{*}(k+1)-i_{C o}(k)=i_{L o}(k+1)-i_{L o}(k)
$$

Comparing (12) with (7) enables the construction of the inner current loop where the control input can be obtained

$$
v_{C}(k)=k_{2}\left(i_{C o}{ }^{*}(k+1)-i_{C o}(k)\right)+\frac{\pi}{2}\left(r_{L o} i_{L o}(k)+v_{o}(k)\right)
$$

where $k_{2}$ is the inner current loop predictive gain. Equation (13) shows that $i_{C o}(k)$ has to be measured for inner current loop 
functionality. However, this is not a necessity since $i_{C o}$ is proportional to change in $v_{o}$. Output voltage $v_{o}(k)$ is measured and $v_{o}(k+1)$ is necessary for realisation of the outer voltage loop (11). The advanced sample $v_{o}(k+1)$ can be predicted using the second order Lagrange quadratic formula

$$
v_{O}(k+1)=3 v_{O}(k)-3 v_{O}(k-1)+v_{O}(k-2)
$$

The predicted sample in advance $v_{o}(k+1)$ can be used to calculate $i_{C o}(k)$

$$
{ }^{i} C_{o}(k)=\frac{C_{O}}{T_{S}}\left(v_{o}(k+1)-v_{o}(k)\right)
$$

Therefore, $i_{C o}(k)$ for the inner current loop can be calculated using (15), with no need to sense it. Fig. 6 shows a schematic of the closed loop structure using the proposed predictive controller.

\section{Closed loop StabiLity}

Considering the block diagram in Fig. 6, the closed loop system transfer function in the discrete $z$-domain can be expressed as

$$
\frac{V_{O}(z)}{V_{O}^{*}(z)}=\frac{\left(\frac{2}{\pi} k_{1} k_{2} T_{S}^{2}\right) z^{2}}{a_{4} z^{4}+a_{3} z^{3}+a_{2} z^{2}+a_{1} z+a_{0}}
$$

where $a_{4}=L_{O} C_{O} \quad, a_{3}=-2 L_{O} C_{O} \quad, a_{2}=L_{O} C_{O}+\frac{4}{\pi} k_{2} C_{O} T_{S}+\frac{6}{\pi} k_{1} k_{2} T_{S}^{2}$, $a_{1}=-\left(\frac{6}{\pi} k_{2} C_{O} T_{S}+\frac{6}{\pi} k_{1} k_{2} T_{S}^{2}\right)$ and $a_{0}=\left(\frac{2}{\pi} k_{2} C_{O} T_{S}+\frac{2}{\pi} k_{1} k_{2} T_{S}^{2}\right)$.

Re-arranging the characteristic equation in (16) to take the form

$$
1+k_{1} G H(z)=0
$$

The root locus can be drawn using the open loop gain $G H(z)$

$G H(z)=\frac{\frac{2}{\pi} k_{2} T_{S}^{2}\left(3 z^{2}-3 z+1\right)}{\left(L_{O} C_{o}\right) z^{4}-\left(2 L_{O} C_{o}\right) z^{3}+\left(L_{O} C_{o}+\frac{4}{\pi} k_{2} C_{O} T_{S}\right) z^{2}-\left(\frac{6}{\pi} k_{2} C_{o} T_{S}\right) z+\frac{2}{\pi} k_{2} C_{o} T_{S}}$

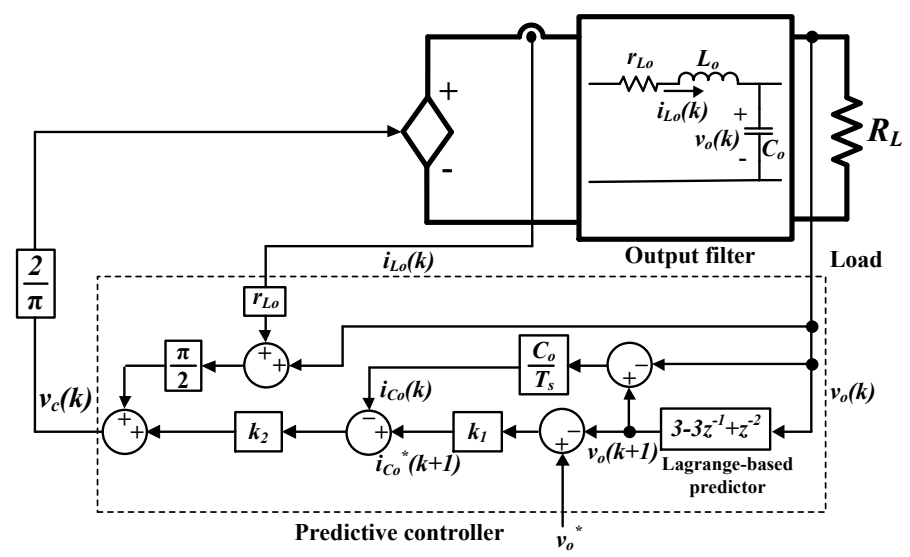

Fig. 6. Closed loop output voltage control using the proposed predictive controller

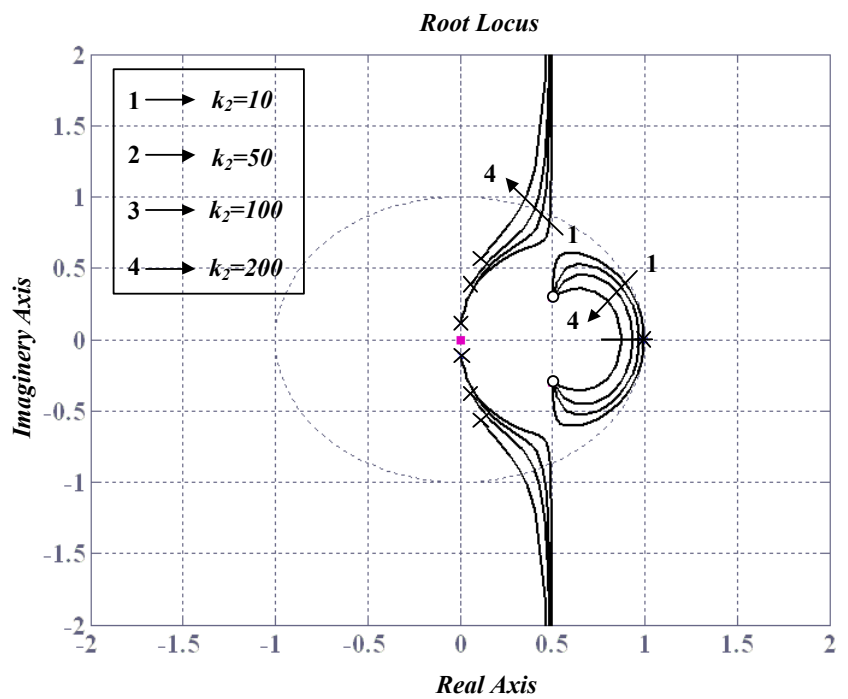

Fig.7. Root loci for system with proposed predictive controller.

In multi-loop control, the inner loop is faster than the outer loop; hence $k_{2}$ is selected to be greater than $k_{l}$. The outer loop is responsible for voltage regulation and overall closed loop stability. Therefore, for a given inner loop controller gain $k_{2}$, the system root locus can be plotted to study the stability limit of the closed loop with respect to change in $k_{l}$. Fig. 7 shows the root loci for the closed loop system with circuit parameter values defined in Table I.

Fig. 7 shows that the closed loop system is more stable with smaller values of $k_{2}$. However, the inner loop dynamics are required to be faster, therefore the $k_{l}<k_{2}$ constrain would result in sluggish dynamic behaviour in the case of low $k_{2}$ gain; hence the trade-off between system speed of response and stability. In addition low gains generally result in poor controller disturbance rejection capability.

\section{SIMULATION AND EXPERIMENTAL RESULTS}

Fig. 8 shows the proposed predictive control algorithm implementation both experimentally and in simulation. Table I summarizes the circuit and control parameter values $\left(k_{l}=0.24\right.$ and $\left.k_{2}=156\right)$. Measurements of the actual SPRC output voltage $\left(v_{o}\right)$ and output filter inductor current $\left(i_{L o}\right)$ are taken; the former to perform voltage control and the latter for state feedback linearization as shown in Fig. 8(a) and (b). The state feedback scheme illustrated in Fig. 5 is implemented in Fig. 8(b). The phase shift angle $\delta$ between the inverter legs is then calculated by the algorithm in Fig. 8(c). All inverter switches are switched with a fixed $50 \%$ duty cycle; the only control variable being the phase shift angle $\delta$ between $S_{1}$ and $S_{3}$ as shown in Fig. 8(d). This controls the effective inverter output voltage duty cycle. The phase-shift angle is updated every switching cycle $(25 \mu \mathrm{s})$.

Fig. 9 shows simulation output voltage results comparing conventional PI control with the proposed predictive controller. Fig. 9(a) and (b) compare responses under step reference voltage $(t=0)$ and step partial to full load $\left(R_{L P L} \rightarrow R_{L F L}\right)$ applied at $t=0.5 \mathrm{~s}$. 
Table I

Resonant Converter Parameter

\begin{tabular}{ll}
\hline \hline \multicolumn{1}{c}{ Parameter } & \multicolumn{1}{c}{ Value } \\
\hline Internal resistance of resonant tank inductor $r_{L s}$ & $0.1916 \Omega$ \\
Resonant tank inductance $L_{s}$ & $100.13 \mu \mathrm{H}$ \\
Parasitic transformer resistance referred to secondary $r_{l}$ & $0.6 \Omega$ \\
Transformer Leakage inductance referred to secondary $L_{l}$ & $9.12 \mu \mathrm{H}$ \\
Total equivalent resistance $r_{T}=r_{l}+r_{L S}$ & $0.7916 \Omega$ \\
Total equivalent inductance $L_{T}=L_{l}+L_{s}$ & $109.25 \mu \mathrm{H}$ \\
Resonant tank series capacitance $C_{s}$ & $0.255 \mu \mathrm{F}$ \\
Resonant tank parallel capacitance $C_{p}$ & $0.255 \mu \mathrm{F}$ \\
Internal resistance of output filter inductor $r_{L o}$ & $0.5 \Omega$ \\
Output filter inductance $L_{o}$ & $12.5 \mathrm{mH}$ \\
Output filter capacitance $C_{o}$ & $120 \mu \mathrm{F}$ \\
Resonant tank fundamental frequency $f_{s}$ & $40 \mathrm{kHz}$ \\
Sampling period $T_{s}$ & $25 \mu \mathrm{s}$ \\
Supply voltage $v_{s}$ & $60 \mathrm{~V}$ \\
Transformer turns ratio $n$ & 0.5 \\
Full-load power rating of experimental test rig & $40 \mathrm{~W}$ \\
Part-load resistive load $R_{L P L}$ & $40.5 \Omega$ \\
Full-load resistive load $R_{L F L}$ & $14.4 \Omega$ \\
Reference output voltage $v_{o}{ }^{*}$ & $24 \mathrm{~V}$ \\
\hline \hline
\end{tabular}

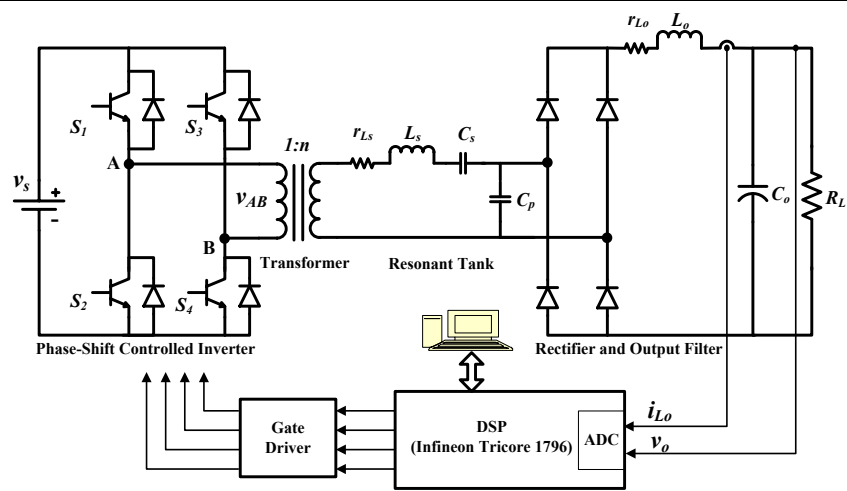

(a)

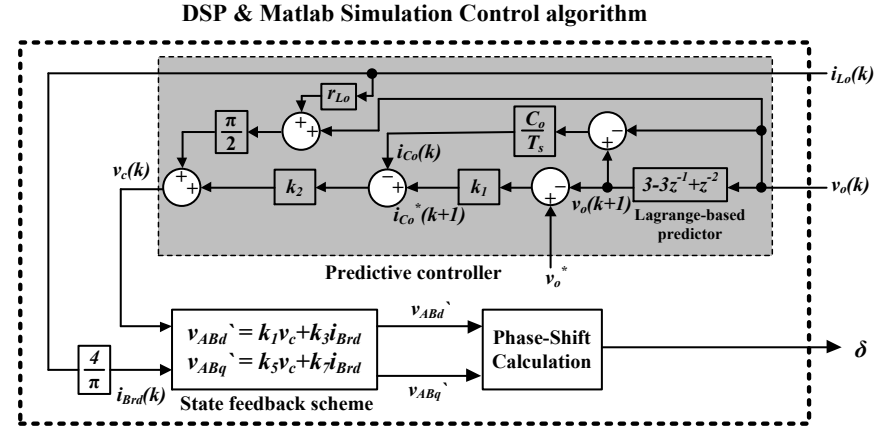

(b)

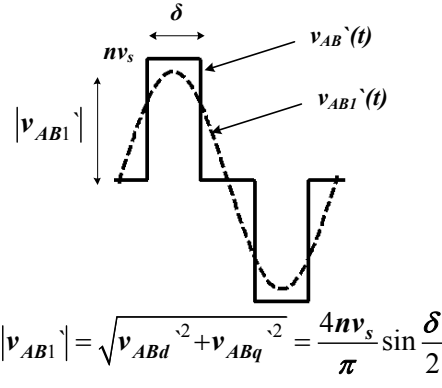

(c)

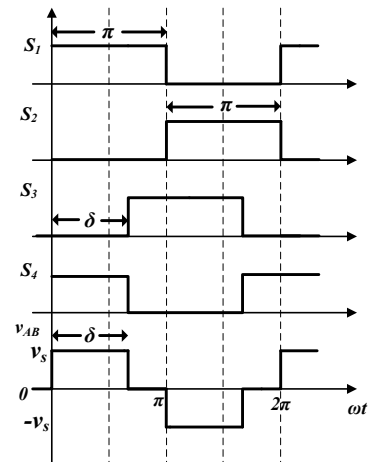

(d)
Fig. 8. Closed loop structure (a) circuit diagram, (b) control algorithm, (c) phase-shift calculator, and (d) inverter phase control gating pattern.
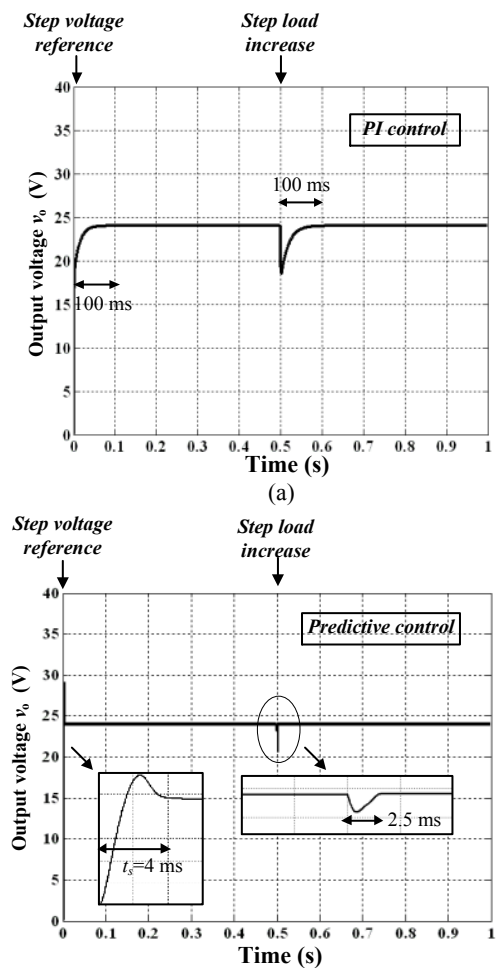

(b)

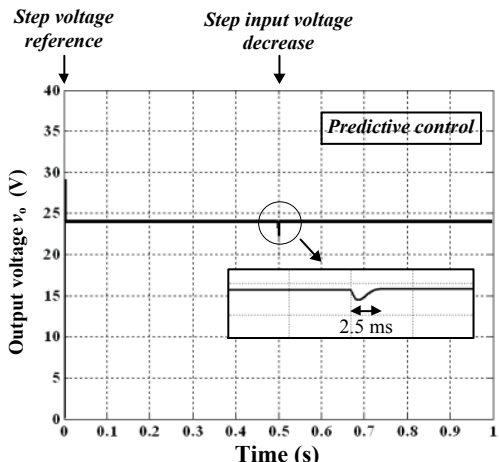

(c)

Fig. 9. Closed loop output voltage simulation results for (a) PI control with step load, (b) proposed predictive controller with step load, and (c) predictive control with step input voltage reduction.

Predictive controller response to step input voltage disturbance $\left(v_{s}=60 \mathrm{~V}\right.$ to $\left.v_{s}=30 \mathrm{~V}\right)$ applied at $t=0.5 \mathrm{~s}$ is illustrated in Fig. 9(c). The proposed predictive controller responds in a faster and robust manner to the applied disturbances compared to PI control. At startup, output voltage reaches desired reference value $\left(v_{o}{ }^{*}=24 \mathrm{~V}\right)$ in $4 \mathrm{~ms}$ compared to $100 \mathrm{~ms}$ for PI control. This is due to the embedded feed forward mechanism that the controller implements which is represented by the $\left(v_{o}+r_{L o} i_{L o}\right)$ term in (13) and which is also represented in Fig. 8(b). Existence of feed forward leads to stabilization of controller response enabling the use of high loop gains to speed up response and increase disturbance rejection capability. Improved robustness and disturbance rejection are apparent from Fig. 9(b) and (c). It takes the predictive controller $2.5 \mathrm{~ms}$ to restore output voltage to reference value after application of both step load and step input voltage disturbances compared to $100 \mathrm{~ms}$ for PI control. Voltage dip is higher with PI control. 


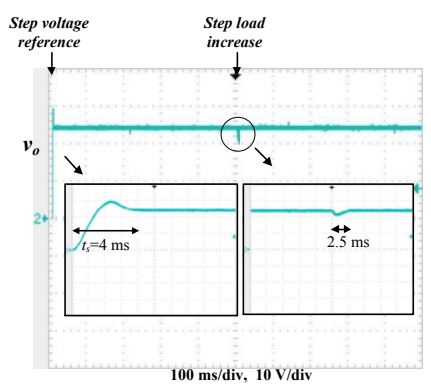

(a)

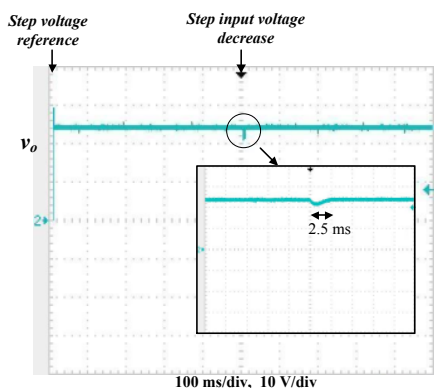

(b)
Fig. 10. Closed loop output voltage experimental results for proposed predictive controller (a) with step load disturbance, and (b) with step input voltage reduction.

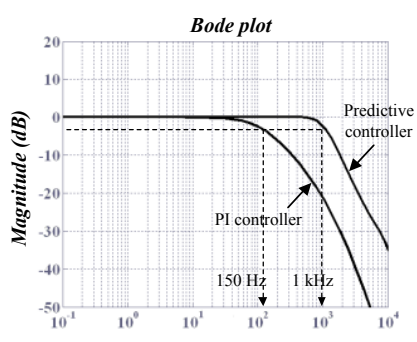

(a)

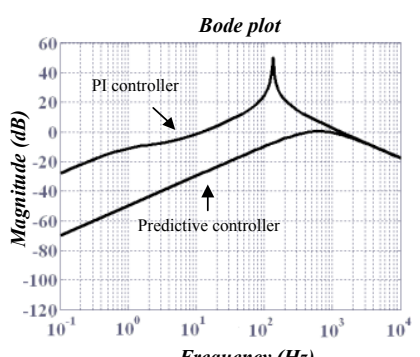

(b)
Fig. 11. Bode plots comparing the proposed predictive controller with PI control (a) closed loop bandwidth and (b) closed loop output impedance.

Fig. 10 depicts experimental results for the proposed predictive controller under the same operational disturbances. Fig. 11(a) shows a closed loop bandwidth comparison for the PI and proposed predictive controllers. The bandwidth of the predictive controller is $1 \mathrm{kHz}$ compared to $150 \mathrm{~Hz}$ for the PI controller; hence the fast controller dynamic response. Fig. 11(b) shows the closed loop output impedance. The proposed controller has greater disturbance rejection capability, due to the higher attenuating nature of the closed loop output impedance compared to PI control.

\section{CONCLUSION}

This paper proposed a new predictive output voltage controller for the phase-controlled SPRC. Controller design is based on a linearized converter large signal model utilising state feedback from output filter inductor current. Closed loop stability was studied and controller gains were selected to ensure stable response. Experimental and simulation results validated the enhanced closed loop output voltage response using the proposed controller in contrast with PI control. Faster dynamics and better robustness are achieved; thanks to the stabilizing feed forward path implemented by the predictive controller; hereby enabling the use of high loop gains.

\section{REFERENCES}

[1] A. K. S. Bhat, "Analysis and design of a series-parallel resonant converter," Power Electronics, IEEE Transactions on, vol. 8, pp. 1-11, 1993.

[2] R. L. Steigerwald, "A comparison of half-bridge resonant converter topologies," Power Electronics, IEEE Transactions on, vol. 3, pp. 174$182,1988$.
[3] M. K. Kazimierczuk, N. Thirunarayan, and S. Wang, "Analysis of series-parallel resonant converter," Aerospace and Electronic Systems, IEEE Transactions on, vol. 29, pp. 88-99, 1993.

[4] I. Batarseh and C. Q. Lee, "High-frequency high-order parallel resonant converter," Industrial Electronics, IEEE Transactions on, vol. 36, pp. 485-498, 1989.

[5] W. Siu-Chung and A. D. Brown, "Analysis, modeling, and simulation of series-parallel resonant converter circuits," Power Electronics, IEEE Transactions on, vol. 10, pp. 605-614, 1995.

[6] V. Agarwal and A. K. S. Bhat, "Small signal analysis of the LCC-type parallel resonant converter using discrete time domain modeling," Industrial Electronics, IEEE Transactions on, vol. 42, pp. 604-614, 1995.

[7] C. L. Chia and E. K. K. Sng, "A Novel Robust Control Method for the Series-Parallel Resonant Converter," Power Electronics, IEEE Transactions on, vol. 24, pp. 1896-1904, 2009.

[8] C. Hao, E. K. K. Sng, and T. King-Jet, "Generalized Optimal Trajectory Control for Closed Loop Control of Series-Parallel Resonant Converter," Power Electronics, IEEE Transactions on, vol. 21, pp. 1347-1355, 2006.

[9] O. Ojo, "Robust control of series parallel resonant converters," Control Theory and Applications, IEE Proceedings -, vol. 142, pp. 401-410, 1995.

[10] Z. Sanbao and D. Czarkowski, "Modeling and Digital Control of a Phase-Controlled Series-Parallel Resonant Converter," Industrial Electronics, IEEE Transactions on, vol. 54, pp. 707-715, 2007.

[11] M. Castilla, L. G. de Vicuna, J. Matas, J. Miret, and J. C. Vasquez, "A Comparative Study of Sliding-Mode Control Schemes for Quantum Series Resonant Inverters," Industrial Electronics, IEEE Transactions on, vol. 56, pp. 3487-3495, 2009.

[12] J. L. Sosa, M. Castilla, J. Miret, L. Garcia de Vicuna, and J. Matas, "Modeling and Performance Analysis of the DC/DC Series-Parallel Resonant Converter Operating With Discrete Self-Sustained Phase-Shift Modulation Technique," Industrial Electronics, IEEE Transactions on, vol. 56, pp. 697-705, 2009.

[13] M. Z. Youssef, H. Pinheiro, and P. K. Jain, "Self-sustained phase-shift modulated resonant converters: modeling, design, and performance," Power Electronics, IEEE Transactions on, vol. 21, pp. 401-414, 2006.

[14] M. K. Kazimierczuk, "Synthesis of phase-modulated resonant DC/AC inverters and DC/DC convertors," Electric Power Applications, IEE Proceedings B, vol. 139, pp. 387-394, 1992.

[15] D. Czarkowski and M. K. Kazimierczuk, "Phase-controlled seriesparallel resonant converter," Power Electronics, IEEE Transactions on, vol. 8, pp. 309-319, 1993.

[16] P. Jain, D. Bannard, and M. Cardella, "A phase-shift modulated double tuned resonant DC/DC converter: analysis and experimental results," in Applied Power Electronics Conference and Exposition, 1992. APEC '92. Conference Proceedings 1992., Seventh Annual, 1992, pp. 90-97.

[17] P. Jain and J. E. Quaicoe, "Modeling and analysis of fixed frequency phase-shift modulated tertiary-side parallel-tuned resonant DC-DC converter," in Industry Applications Society Annual Meeting, 1993., Conference Record of the 1993 IEEE, 1993, pp. 1081-1089 vol.2.

[18] P. Jain, H. Soin, and M. Cardella, "Constant frequency resonant DC/DC converters with zero switching losses," Aerospace and Electronic Systems, IEEE Transactions on, vol. 30, pp. 534-544, 1994.

[19] Z. Sanbao and D. Czarkowski, "Dynamics of a phase-controlled seriesparallel resonant converter," in Circuits and Systems, 2002. ISCAS 2002. IEEE International Symposium on, 2002, pp. 819-822.

[20] I. Batarseh and K. Siri, "Generalized approach to the small signal modelling of DC-to-DC resonant converters," Aerospace and Electronic Systems, IEEE Transactions on, vol. 29, pp. 894-909, 1993. A.

[21] A. Aboushady, K. H. Ahmed, S. J. Finney, and B. W. Williams, "State feedback linearized model for phase-controlled series-parallel resonant converters," in IECON 2011 - 37th Annual Conference on IEEE Industrial Electronics Society, 2011, pp. 1590-1595.

[22] Z. M. Ye, P. K. Jain, and P. C. Sen, "Multiple frequency modeling of high frequency resonant inverter system," in Power Electronics Specialists Conference, 2004. PESC 04. 2004 IEEE 35th Annual, 2004, pp.4107-4113,Vol.6. 